\title{
The Dissociation Constants of some Phosphorus(V) Acids
}

\author{
C. J. PeAcock * and G. Nickless \\ Department of Inorganic Chemistry, University of Bristol, England \\ (Z. Naturforsch. 24 a, 245-247 [1969] ; received 25 September 1968)
}

\begin{abstract}
The dissociation constants of ortho-, monothio-, monoamido- and diamido-phosphoric acids have been measured at a series of temperatures using a potentiometric titration method involving computer fitting of the theoretical titration curve to the experimental one, the constants being used as adjustable parameters. Less accurate values for diamidothio- and tetrathio-phosphoric acids were also obtained.

The results are discussed with respect to the site of protonation. For the monothio acid only the first dissociation $\left(K_{1}\right)$ appears to involve the sulphur atom. The monoamido compound may be protonated first on nitrogen $\left(K_{2}\right)$. The diamido- and diamidothio-phosphoric acids show a remarkable effect in that, although monoanionic, two $p K_{a}$ values may be measured, the first protonation $\left(K_{2}\right)$ being probably onto nitrogen, the second $\left(K_{1}\right)$ involving the oxygen atom more.
\end{abstract}

For measuring dissociation constants of acids with no measurable U.V. or visible spectra, as the phosphorus $(V)$ acids, it is necessary to use conductivity or potentiometric titration methods. If the compounds are relatively unstable as acids one wishes to work as far as possible with the salts, so conductivity methods are not available. The normal procedure for potentiometric titrations is to titrate the salt with acid until it is half ionized, whence as $p K_{a}=p_{\mathrm{H}}+\log ([$ acid $] /[$ salt $])$ and the acid and salt activities are equal, the $p K_{a}$ is given, after some corrections, by the $p_{\mathrm{H}}$ at this point. However the method is wasteful on data, effectively only one point on the whole curve being used. It is possible however to calculate the shape of the titration curve, and using the dissociation constants as adjustable parameters fit this to the experimental data. This also allows for the corrections needing to be made for the volume of acid added, proton transfer etc.

If the volume of acid of normality $A$ added to a mixture of $B$ mmoles of strong base and $B_{\mathrm{W}}$ mmoles of a weakly dibasic salt is $v \mathrm{mls}$, then:

$$
A=B-\frac{K_{\mathrm{W}}(V+\nu)}{H}+H(V+\nu)+\frac{B_{\mathrm{W}}\left(2 H^{2}+H K_{1}\right)}{H^{2}+H K_{1}+K_{1} K_{2}}
$$

where the initial volume of solution was $V \mathrm{mls}$, the hydrogen ion concentration is $H$, and $K_{1}, K_{2}$ and $K_{\mathrm{W}}$ are the dissociation constants of the weak base and ionic product of water respectively.

The change of hydrogen ion concentration with volume is hence given by

$$
\begin{aligned}
\frac{\mathrm{d} H}{\mathrm{~d} v}= & \left(\frac{A+K_{\mathrm{W}}-H}{H}\right) / \\
& \left(\frac{\left(K_{\mathrm{W}}+H^{2}\right)(V+v)}{H}+\frac{B_{\mathrm{W}} K_{1}\left(H^{2}+4 H K_{1}+K_{1} K_{2}\right)}{H^{2}+H K_{1}+K_{1} K_{2}}\right)
\end{aligned}
$$

This differential equation may be integrated and the curve shape calculated. This was done automatically by the computer program.

The various data affected the calculated curve thus: dissociation constants only in the region of $\pm 2 p \mathrm{~K}$ units around their value; $K_{\mathrm{W}}$ between $p_{\mathrm{H}} 7$ and $9, A$ around $p K_{1}$ and $p_{\mathrm{H}} 7, B_{\mathrm{W}}$ around $p K_{1}$ and $p K_{2}$ but if $B_{\mathrm{W}}$ was calculated from the titration curve using the value of $A$ small errors in $A$ had little affect on the curve; changes in $V$ displaced the whole curve slightly.

Thus the titration was performed using a solution of the salt of the weak acid containing a few drops of strong base so that both inflection points appear on the titration curve, and $B_{W}$ could be calculated from the volume added between them. The data were taken from the region where the curve shape was sensitive to variation of the dissociation constants. Initial values of these constants were calculated from the midpoint of the two inflections.

The quantity calculated is the hydrogen ion concentration, but that measured by a $p_{\mathrm{H}}$ meter is the activity. Thus a parameter linking the two was introduced. Attempts were made to calculate it from Debye-Hückel theory; treat it as a variable of the form given by this theory; or just considering it a constant over the whole titration. The last gave just as consistent results and involved the least calculation so was always used. The value of this mean activity coefficient always fell between 0.8 and 0.95 .

The calculations were performed using a computer program which integrated the differential equa-

* Present address: Dept. of Chemistry, The University, Southampton, SO9 5NH, England. 
tion by a Runga Kutta method for each combination of parameters and performed a least squares fit on the data by adjusting the parameters. The final fit resulted in the calculated and theoretical curves being always within $0.02 p_{\text {II }}$ units of each other.

Measurements were performed at a series of temperatures and the final values smoothed using the function $T p K_{a}=a+b T+c T^{2}$. Both smoothed and unsmoothed values are given in Table 1 . It is seen that the r.m.s. variation of the two for any one set is at most 0.05 units. Taking into account the error due to using mean activity coefficients, the uncertainty on the ionic strength, and the error on the data constants it is thought that the error on the smoothed $p K_{a}$ values will not exceed 0.05 units. All values are relative to a $p_{\mathrm{H}}$ scale taking that of an $0.05 \mathrm{~m}$ aqueous solution of potassium hydrogen phthalate as being 4.000 at $15^{\circ} \mathrm{C}$.

\section{Experimental}

Measurements were made in a $250 \mathrm{ml}$ five-necked reaction vessel fitted with the two $p_{\mathrm{H}}$ meter electrodes (E.I.L. GHS 33 screened glass above $15^{\circ} \mathrm{C}$, E.I.L. GHC 33 screened glass below $20^{\circ} \mathrm{C}$; calomel (saturated $\mathrm{KCl}$ reference); thermometer; burette; coldwater condenser and nitrogen bleed. The recording was done on a Vibron $39 \mathrm{~A} p_{\mathrm{H}}$-meter. The ap- paratus was brought up to temperature containing distilled water and the electrodes were equilibrated at this temperature for at least 12 hours. Temperature control was obtained by immersing the apparatus in a waterbath controlled to within $0.1{ }^{\circ} \mathrm{C}$ by a Tecam "Tempunit". The water was then carefully poured out leaving any condensed on the vessel and condenser sides as far as possible untouched, for at higher temperatures this could be $2-3 \mathrm{ml}$, enough to introduce an error of $0.01 p_{\mathrm{H}}$ units. The prewarmed salt solution was then poured in and the assembly left to come to equilibrium again. A stream of nitrogen served to stir the solution and remove any contaminating carbon dioxide.

Immediately before titration the electrodes were standardized against $0.05 \mathrm{~m}$ potassium hydrogen phthalate solution.

For titrations of thio-phosphates the nitrogen stream passed through a solution of silver nitrate after leaving the titration vessel, so that any decomposition could be monitored. For monothiophosphate at $35^{\circ} \mathrm{C}$ only $2 \%$ decomposition had occurred by the end of the measurements.

The salt solution was made up of $200 \mathrm{ml}$ of $0.05 \mathrm{~m}$ phosphorus anion, plus potassium chloride and a few drops of potassium hydroxide to bring the initial $p_{\mathrm{H}}$ up to 11 or so, and the initial ionic strength to

\begin{tabular}{|c|c|c|c|c|c|c|c|}
\hline \multirow[b]{2}{*}{ Ion } & \multirow[b]{2}{*}{ Temp. ${ }^{\circ} \mathrm{C}$} & \multicolumn{2}{|c|}{$p K_{1}$} & \multicolumn{2}{|c|}{$p K_{2}$} & \multicolumn{2}{|c|}{$p K_{3}$} \\
\hline & & Measured & Smoothed & Measured & Smoothed & Measured & Smoothed \\
\hline \multirow[t]{6}{*}{$\mathrm{PO}_{4}{ }^{3-}$} & 0.2 & 1.610 & 1.713 & 6.781 & 6.730 & \multirow{6}{*}{ Not 1} & \\
\hline & 22.0 & 1.859 & 1.860 & 6.704 & 6.690 & & \\
\hline & 22.1 & 1.803 & 1.861 & 6.691 & 6.694 & & sured \\
\hline & 30.0 & 1.983 & 1.937 & 6.724 & 6.715 & & \\
\hline & 40.0 & 1.998 & 2.008 & 6.704 & 6.718 & & \\
\hline & 50.0 & 2.104 & 2.108 & 6.725 & 6.726 & & \\
\hline \multirow{5}{*}{$\mathrm{PO}_{3} \mathrm{~S}^{3^{-}}$} & 10.0 & 1.265 & 1.265 & 5.254 & 5.280 & 10.294 & 10.29 \\
\hline & 16.0 & 1.517 & 1.517 & 5.382 & 5.390 & 10.175 & 10.19 \\
\hline & 19.0 & - & - & 5.378 & 5.401 & 10.154 & 10.13 \\
\hline & 25.0 & 1.788 & 1.788 & 5.413 & 5.427 & 10.092 & 10.08 \\
\hline & 32.2 & - & 一 & 5.400 & 5.428 & 10.009 & 10.00 \\
\hline \multirow{5}{*}{$\mathrm{PO}_{3} \mathrm{NH}_{2}{ }^{2-}$} & 6.0 & 2.735 & 2.610 & 8.403 & 8.422 & & \\
\hline & 26.5 & 2.738 & 2.739 & 8.050 & 8.102 & & \\
\hline & 33.0 & 2.758 & 2.731 & 7.978 & 7.950 & & \\
\hline & 40.0 & 2.708 & 2.716 & 7.865 & 7.896 & & \\
\hline & 46.3 & 2.696 & 2.696 & 7.808 & 7.821 & & \\
\hline \multirow{5}{*}{$\mathrm{PO}_{2}\left(\mathrm{NH}_{2}\right)_{2}^{-}$} & 0.0 & 1.118 & 1.051 & 5.279 & 5.299 & & \\
\hline & 8.0 & 1.140 & 1.098 & 5.182 & 5.103 & & \\
\hline & 21.4 & 1.148 & 1.194 & 4.978 & 4.998 & & \\
\hline & 30.0 & 1.221 & 1.279 & 4.870 & 4.889 & & \\
\hline & 40.0 & 1.451 & 1.400 & 4.803 & 4.780 & & \\
\hline
\end{tabular}

Table 1. $p K_{a}$ values for ortho-, monothio-, monoamido- and diamidophosphoric acids over a range of temperatures. Measured values from individual experiments; smoothed ones from best fit to curve $T \cdot p K_{a}=a+b T+c T^{2}$. 
0.5 mole ion/litre. The variation of ionic strength during the titration, due both to adding acid and removing phosphate anions, was less than 0.2 mole ion/litre. The phosphorus concentration was determined independently each time by the molybdovanadate yellow colourimetric method, and always agreed with that calculated from the titration to within the accuracy of the method $(1-2 \%)$. The purities of all anions were checked by quantitative ion exchange chromatography, and were always better than $98 \%$. The titrant was approximately molar analytical reagent grade hydrochloric acid, standardized against borax.

\section{Results and Discussion}

The results are given in Table 1 , and in Table 2 are various values reported in the literature for monoamidophosphate.

\begin{tabular}{cclcc}
\hline Temp. ${ }^{\circ} \mathrm{C}$ & $p K_{1}$ & $p K_{2}$ & Concentration & Ref. \\
\hline 10 & 4.6 & 7.7 & - & $\mathrm{a}$ \\
20 & 2.92 & 7.68 & - & $\mathrm{b}$ \\
20 & 2.36 & 8.35 & $\mu=0.3$ & $\mathrm{c}$ \\
25 & 3.00 & 8.15 & $0.2 \mathrm{~m}$ & $\mathrm{~d}$ \\
25 & - & 7.95 & $0.5 \mathrm{~m} \mathrm{KCl}$ & $\mathrm{e}$ \\
25 & - & 8.2 & - & $\mathrm{f}$ \\
40 & 2.90 & 7.70 & $\mu=0.05$ & $\mathrm{c}$ \\
\hline
\end{tabular}

a M. Halmann, A. Lapidot, and D. Samuel, J. Chem. Soc. $1963,1299$.

b R. Klement, G. Biberacher, and V. Hille, Z. Anorg. u. Allg. Chemie 289, 80 [1957].

c C. J. Peacock, B. Sc. Thesis. University of Bristol (England) [1964].

d J. D. Chanley and E. Feageson, J. Amer. Chem. Soc. 85, 1181 [1963].

e T. L. Muller, Acta Biochem. Biophys. 16, 163 [1955].

T. Rathler and T. Rosenberg, Arch. Biochem. Biophys. 65, 319 [1956].

Table 2. $p K_{a}$ values for monoamidophosphoric acid taken from the literature.

In comparing dissociation constants it is not easy to disentangle the dissociation from the changes in solvation of the ion. It has been suggested however ${ }^{1}$ that straight forward comparison of the $p K$ values at a standard temperature (and hence of the standard free energy change $\Delta G^{0}$ ) is valid, provided only large changes in $p K$ values ( 2 units or more) are interpreted. In Table 3 are given values of the

1 R. P. Bell, The Proton in Chemistry (Methuen, London) 1959 , pp. 69 et seq.

2 J. R. van Wazer, Phosphorus and its Compounds. Vol. 1 (Interscience, New York) 1959, p. 360. $p K$ 's at $20^{\circ} \mathrm{C}$ both for the molecules exactly measured, and two others measured to less accuracy.

\begin{tabular}{lllc}
\hline \multicolumn{1}{c}{ Anion } & $p K_{1}$ & $p K_{2}$ & $p K_{3}$ \\
\hline $\mathrm{PO}_{4}{ }^{3-}$ & 1.85 & 6.69 & $\left(12.3^{2}\right)$ \\
$\mathrm{PO}_{3} \mathrm{~S}^{3-}$ & 1.67 & 5.40 & 10.14 \\
$\mathrm{PS}_{4}{ }^{3-}$ & 1.8 & 3.5 & 6.6 \\
$\mathrm{PO}_{3} \mathrm{NH}_{2}{ }^{2-}$ & 2.74 & 8.17 & - \\
$\mathrm{PO}_{2}\left(\mathrm{NH}_{2}\right)_{2}{ }^{-}$ & 1.18 & 5.00 & - \\
$\mathrm{POS}\left(\mathrm{NH}_{2}\right)_{2}-$ & 2.0 & 4.3 & - \\
\hline
\end{tabular}

Table 3. $p K_{a}$ values at $20^{\circ} \mathrm{C}$ for various amido- and thio-phosphates.

From the magnitudes of the $p K^{\prime}$ 's it ought be possible to learn something of the site of protonation of the anions. Comparing monothiophosphate with ortho- and tetrathio-phosphate shows immediately that the first protonates on oxygen for the first two steps, but the $p K_{1}$ values of all three are so similar, that this protonation probably involves both possible sites, oxygen and sulphur.

It is remarkable that diamido- and diamidothiophosphates should have two $p K_{a}$ values, they being monoanionic. Clearly one protonation is on nitrogen. Comparison with hypophosphorous acid ( $p K$ $\left.=1.1^{2}\right)$ shows that the first $\left(p K_{2}\right)$ must be onto nitrogen, but that the second protonation probably mainly involves the oxygen. Whether the higher $p K_{1}$ of the thio compound indicates increased participation of nitrogen is unclear. Attempts to isolate the cationic species have been unsuccessful.

Monoamidophosphate failed to show a third $p K$ value, but comparison with phosphorous acid ( $p K_{1}$ $1.3 ; p K_{2} 6.7^{2}$ ) leads one to suspect different ionization patterns for these two compounds. The $p K$ difference $(1.4-1.5$ units $)$ is just about on the limit of significance, and so could indicate that the first protonation is on nitrogen (cf. in the solid the monoanion exists as ${ }^{\oplus} \mathrm{H}_{3} \mathrm{~N}-\mathrm{PO}_{3}{ }^{\ominus}$ ), and the second on oxygen, but the evidence is very far from being conclusive.

\section{Conclusion}

The acid dissociation constants seem to give quite good information regarding protonation sites for the monothio-, diamido- and diamidothio-phosphate ions. It is hoped to study some of the other members of the amidothiophosphates by this method, and also to make further investigations using Raman spectroscopy of the aqueous solutions.

One of the authors (C. J. P.) wishes to thank the Science Research Council for financial support during the period of this work. We also wish to thank Dr. J. S. LitTLER who devised the computer program used. 